Original Research Paper

\title{
Investigation of Oocyte Retrieval Methods and Maturation Media on in vitro Development of Porcine Embryos
}

\author{
${ }^{1}$ Kayla M. Honneysett, ${ }^{2}$ Masindi L. Mphaphathi, ${ }^{1}$ Edward C. Webb and ${ }^{1}$ Ayanda Maqhashu \\ ${ }^{1}$ University of Pretoria, Department of Animal Sciences, Faculty of Natural and Agricultural Sciences, \\ Pretoria, 0002, South Africa \\ ${ }^{2}$ Agricultural Research Council, Animal Production, Germplasm Conservation and Reproductive Biotechnologies, \\ Private Bag X 2, Irene, 0062, South Africa
}

Article history

Received: 17-03-2021

Revised: 13-05-2021

Accepted: 20-05-2021

Corresponding Author:

Masindi L Mphaphathi

Agricultural Research Council,

Animal Production,

Germplasm Conservation and

Reproductive Biotechnologies,

Private Bag X 2, Irene, 0062,

RSA.

Email: masindim@arc.agric.za

\begin{abstract}
The objectives of the study were to compare oocyte retrieval methods (aspiration and slicing) from pig ovaries on oocyte quality and quantity; compare in vitro maturation (IVM) media (North Carolina State University-NCSU 37, Tissue Culture Medium-TCM 199 and porcine follicular fluid-mpFF) on oocytes polar body extrusion; compare the effect of electrical stimulation (ES) and frozen-thawed semen on cleavage rates and compare the effect of culture media, cNCSU 37 and cpFF, on cleavage rates. Follicular fluid collected from the retrieval methods was assessed for the presence of oocytes and categorized as either Grades A, B, or C. Grades A and $\mathrm{B}$ oocytes were randomly allocated per treatment groups, matured for $44 \mathrm{~h}$ and checked for polar body extrusion. Matured oocytes were randomly allocated to either ES or traditional in vitro fertilization (IVF) with frozenthawed semen. The ES and IVF took place in conjunction with in vitro culture (IVC) media. Zygotes were checked for cleavage and recorded. The treatment means were compared using the Fisher's protected t-test least significant difference. Slicing had significantly higher amounts of Grade A (58.7\%) and Grade B (50.8\%) oocytes than the aspiration method. Oocytes polar body extrusion were $25.3,84.2$ and $73.8 \%$ for NCSU 37, TCM 199 and mpFF respectively. Zygotes cleavage was $48.1 \%$ for traditional IVF and $56.8 \%$ for ES; $66.6 \%$ for cNCSU 37 and $45.7 \%$ for cpFF. Slicing proved to be better than the aspiration method for the total amount of Grades A and B oocytes retrieved. The TCM 199 and mpFF media had a higher percentage of oocytes with polar body extrusion than NCSU 37. Cleavage rate of zygotes was higher when using ES and cNCSU 37.
\end{abstract}

Keywords: Porcine Ovaries, Follicular Fluid, Semen, IVF, IVC

\section{Introduction}

The use of assisted reproductive technologies (ARTs) in the porcine industry will allow for an increase in reproductive efficiency. As well as an increase in the productivity of the industry for the supply of pork products (Romar et al., 2016; 2019). While pork products are highly consumed in other countries, in South Africa it is not a popular source of protein (Davids et al., 2014). The reason for the lack of popularity of pork could be contributed to specific religious preferences of consumers within South Africa, the high cost of meat due to high production costs and importation of pork from other countries (Robinson, 2018). Pork products have been shown to be a valuable food source, but due to its lack of popularity in South Africa it is not viewed as such. Therefore, once it is recognised for its value, the demand for pork products will begin to increase (Tait-Burkard et al., 2018; Romar et al., 2019). This shows that there is an opportunity to improve the efficiency of the pig production industry in South Africa to decrease the importation of pork and thereby become more self-sufficient. This will allow for the average cost of pork to decrease and become more affordable for the poorer communities in order to become a more popular source of protein.

The application of ARTs during in vitro embryo production (IVEP) can be defined as successful when immature oocytes are recovered, matured and fertilized in vitro to reach the blastocyst stage post culturing (Nedambale et al., 2004; Lekola, 2015). The use of IVEP 
technologies are used in circumstances where multiple ovulation and embryo transfers cannot be utilized; such as when using prepubertal females, gestating or slaughtered animals for reproduction purposes (Armstrong et al., 1992; 1994; Hasler, 1994; Baldassarre et al., 1996).

The efficiency of using ARTs for porcine germplasm has been shown to be lower than in other species, especially cattle (Kikuchi et al., 2002; Schoevers et al., 2003; Alvarez et al., 2009). This can be seen through the success rate following in vitro fertilization (IVF), with that in porcine being approximately $45 \%$ while in vitro production in cattle has a $70 \%$ success rate (Romar et al., 2016; 2019). While Gil et al. (2010) found a 30-50\% efficiency in porcine IVF, which was lower compared to cattle, because polyspermic embryos develop to the blastocyst stage at the same rate as healthy embryos. Therefore, reproductive technologies that are currently used for porcine germplasm have drawbacks due to the high rate of polyspermy which leads to poor development rates and low quality blastocysts (Nagai et al., 2006; Gil et al., 2010; Pyoos et al., 2018). It has been shown that embryo transfers from embryos that have been cultured in vitro can result in low pregnancy rates and high embryo mortality rates (Funahashi et al., 1997; Long et al., 1999).

The in vitro production of porcine embryos is less effective than in vivo embryos (Kikuchi et al., 1999; Yoon et al., 2000; Tatemoto et al., 2004). Although, advancing the use of porcine reproductive technologies will allow for better results and for further use of other technologies. By improving the technologies used for in vitro procedures the efficiency of production of porcine embryos in South Africa can significantly improve. This would be particularly important for the South African pork industry as there is currently little information on how to use these biotechnologies within the farming community in order to close the pork consumption gap with other countries. The aim of the study was to investigate the maturation, fertilization and culturing media and techniques for porcine embryos produced in vitro.

\section{Materials and Methods}

\section{Chemicals, Reagents and Animal Ethics}

The chemicals used in the study were obtained from Sigma-Aldrich prior to the commencement of the study. In brief, the in vitro maturation (IVM), IVF and in vitro culture (IVC) media were prepared and used within two weeks. Ethical clearance was obtained from Agricultural Research council- animal production (ARC-AP), germplasm, conservation, reproduction and biotechnologies (GCRB) laboratories (APAEC 2019/24) as well as from the University of Pretoria ethical committee (ARC-AP, NAS215/2020).

\section{Collection of Ovaries and Oocyte Retrieval}

The ovarian tissue was obtained from prepubescent gilts of unknown breeds from the local abattoir. The collected ovaries were placed in a thermos flask and covered with $0.9 \% \mathrm{NaCl}$ saline solution at $39^{\circ} \mathrm{C}$ and transported from the abattoir to the laboratory within one hour after slaughter.

Using the aspiration technique, an 18-gauge needle was attached to a $10 \mathrm{~mL}$ syringe and inserted into the ovary surface to remove the oocytes from medium sized follicles (3-6 mm diameter). The follicular fluid collected inside the syringe was placed into a $50 \mathrm{~mL}$ tube containing $5 \mathrm{~mL}$ of modified Dulbecco Phosphate Buffered Saline (mDPBS). During the slicing technique the ovaries were placed in a petri dish containing $5 \mathrm{~mL}$ of $\mathrm{mDPBS}$. A handheld pin was used to hold the ovary in place while a size 22 surgical blade cut through the entire ovary multiple times. The remaining fluid inside the petri dish was poured into a $50 \mathrm{~mL}$ tube. The supernatant was then gently removed using a Pasteur pipette without disturbing the pellet.

\section{Washing and Grading of Oocytes}

Six dishes (Falcon 1008) were prepared with three dishes containing $3 \mathrm{~mL}$ of $\mathrm{mDPBS}$ each and the remaining three dishes containing $3 \mathrm{~mL}$ of TCM 199 supplemented with $10 \%$ of foetal bovine serum (FBS). The dishes were placed in the incubator at $38.5^{\circ} \mathrm{C}$ prior to oocyte washing. The oocytes were then washed three times with $\mathrm{mDPBS}$ and thereafter washed a further three times with TCM 199 supplemented with $10 \%$ of FBS with the aid of a handheld pipette. The oocytes were graded under the stereo microscope and classified into Grades of A, B, or C (Hamano and Kuwayama, 1993; Khandoker et al., 2001; Kumar et al., 2016). Only Grade A and B oocytes were selected for use in IVM and Grade C oocytes were discarded.

\section{In vitro Maturation of Oocytes and Polar Body Evaluation}

A total of $500 \mu \mathrm{L}$ of each of the IVM media (NCSU 37, TCM 199 and mpFF) was placed in a four well dish and covered with $250 \mu \mathrm{L}$ of mineral oil, to prevent evaporation. The grade A and B oocytes were then placed in the prewarmed IVM media and incubated at $38.5^{\circ} \mathrm{C}$ with $5 \%$ $\mathrm{CO}_{2}$ for $44 \mathrm{~h}$. The oocytes were removed from the IVM media at the end of the IVM period of $44 \mathrm{~h}$ (Yamauchi et al., 1996; Agung et al., 2013). Matured oocytes were then placed in an eppendorf tube with $200 \mu \mathrm{L}$ of prewarmed TCM 199 and then vortexed (Zeringue et al., 2005). Following this process, the denuded oocytes were then transferred to a mini petri dish containing $3 \mathrm{~mL}$ of TCM 199. The oocytes polar body extrusion was evaluated with the aid of Oosight Imaging System connected to an inverted research microscope and recorded per treatment.

\section{In vitro Fertilization of Oocytes and Sperm Motility Evaluation}

Frozen semen straws used for IVF were removed from a liquid nitrogen tank using forceps. The frozen straw was held in the air for $10 \mathrm{sec}$, then plunged into a warm $\left(37^{\circ} \mathrm{C}\right)$ 
water container for $1 \mathrm{~min}$. The straw was then patted dry using paper towels before one side of the semen straw was cut and poured into $8 \mathrm{~mL}$ of prewarmed IVF media. The IVF-semen solution was centrifuged at $2000 \mathrm{rpm}$ at $36^{\circ} \mathrm{C}$. The supernatant was removed with a Pasteur pipette and replaced with another $8 \mathrm{~mL}$ of IVF media. The solution was then centrifuged once again and the supernatant removed. The sperm pellet was then diluted with IVF media.

Prior to IVF taking place, the computer assisted sperm analysis system, Sperm Class Analyzer ${ }^{\circledR}\left(\mathrm{SCA}^{\circledR}\right)$, was used to determine sperm motility and velocity traits. A total of $5 \mu \mathrm{L}$ of the frozen-thawed semen sample was placed on a warmed microscope slide and cover slip. The microscope slide was placed on a warming plate adjusted at $37^{\circ} \mathrm{C}$ prior to the placement of semen sample and cover slip. The microscope slide was then placed onto the $\mathrm{SCA}^{\circledR}$ system and two to three fields were captured for assessment. The capturing took place at 10x magnification in order to track each individual sperm and the $\mathrm{SCA}^{\circledR}$ software was used to record the images. The fields captured were then examined for possible debris to be removed manually.

The matured oocytes were washed five times in previously prepared dishes (Falcon 3801) containing 100 $\mu \mathrm{L}$ drops of the IVF media covered with $3 \mathrm{~mL}$ of mineral oil. The oocytes were allocated into a dish previously prepared with seven $50 \mu \mathrm{L}$ drops of the IVF media covered with $3 \mathrm{~mL}$ of mineral oil. A total of $50 \mu \mathrm{L}$ of the semen/sperm was added to each $50 \mu \mathrm{L}$ drop (final volume of $100 \mu \mathrm{L}$ ) containing oocytes. The IVF dish was then placed in an incubator for $24 \mathrm{~h}$ at $5 \% \mathrm{CO}_{2}$ at $38.5^{\circ} \mathrm{C}$.

\section{Electrical Stimulation of Oocytes}

Matured oocytes were washed five times in previously prepared $100 \mu \mathrm{L}$ drops of electrical stimulation (ES) media covered with $3 \mathrm{~mL}$ of mineral oil. The matured oocytes were then placed in the ES media for $1 \mathrm{~min}$ prior to and $3 \mathrm{~min}$ post stimulation. The oocytes were placed between the $0.5 \mathrm{~mm}$ gap in a BTX Model 450 dish. The dish was then connected to the BTX ECM 2001 Electro Cell Manipulator and given $4 \mathrm{~V} / \mathrm{mm}$ AC for $10 \mathrm{sec}$ and thereafter 2 pulses of $60 \mathrm{~V} / \mathrm{mm}$ DC for $60 \mu \mathrm{sec}$, with two repeats.

\section{In vitro Culture of Embryos}

The IVC of embryos was done immediately following ES and $24 \mathrm{~h}$ post IVF. The zygotes from the ES and IVF treatments were divided into two groups and allocated to the IVC media, cNCSU 37 and cpFF. The zygotes were washed 3 times in TCM 199 and thereafter washed 5 times in previously prepared $100 \mu \mathrm{L}$ drops, covered with $3 \mathrm{~mL}$ of mineral oil, of either cNCSU 37 or cpFF media. The washed zygotes were then placed in $50 \mu \mathrm{L}$ of the corresponding prepared IVC media covered with $3 \mathrm{~mL}$ of mineral oil. The dishes were then immediately put into a modulator incubator chamber with $90 \% \mathrm{CO}_{2}$ at $38.5^{\circ} \mathrm{C}$ for $48 \mathrm{~h}$. Two days post IVC, the embryos were removed from the incubator and checked under the microscope for cleavage. The embryos were visually judged and grouped, according to cleavage cell number, into 1 cell, $2-4$ cell, $8+$ cell and lysed. The cleavage percentage was then recorded.

\section{Statistical Analysis}

Data collected was analysed using an analysis of variance (ANOVA). The treatment means were compared using the Fisher's protected t-test least significant differences (LSD) and a Shapiro-Wilk's test was used to test for deviations from normality (Shapiro and Wilk, 1965). The least significant differences were evaluated at a $\mathrm{P}<0.05$; where a $5 \%$ significance level was used for the comparison of treatment means. The data was analysed using the statistical software SAS version 9.4 (SAS, 1999).

\section{Results and Discussion}

The results of this study show that there were significant differences between the oocyte removal techniques. Of the 682.4 oocytes collected over the entirety of the initial study, only $28.4 \%$ of those were collected using the aspiration method (Table 1). The majority of oocytes collected were obtained through the slicing method, with $71.6 \%$ of the 682.4 oocytes collected using this method. It can then be deduced that the slicing method provides the highest amount of oocytes during collection when compared to aspiration. Marques et al. (2015) found similar results, showing that the slicing method produced a higher amount of oocytes than the aspiration method.

In this study, high quality oocytes were the grouping of both Grade A and B oocytes (Fig. 1), while the rest of the oocytes were Grade C. Using the aspiration method 193.8 oocytes were collected over the course of the study, of these oocytes collected, only $50.8 \%$ were placed into the high quality classification. Whereas with the slicing method, of the 488.6 oocytes collected, only $58.7 \%$ of those were of high quality. These findings were not in accordance with Lekola (2015) who found no significant differences between the quality of bovine oocytes when using the aspiration or slicing method. Marques et al. (2015) found that the aspiration method was the method of choice for later reproductive technologies $(p=0.0395)$. While they found the slicing method to produce a higher quantity of oocytes, their later study showed that there were no differences between oocyte recovery methods until day 7 post IVF. Furthermore, maturation rates between the two methods had no significant difference, nor did the cleavage rates at day 3 post IVF (Marques et al., 2015).

Further study may be undertaken using different oocyte removal techniques from pig ovaries. Other methods such as 
cutting method could be used, although may be labour intensive with requirements for certain equipment (Hamano and Kuwayama, 1993). The puncture method is another method that may be explored although it appears to have a similar process to the aspiration method (Shirasawa et al., 2013).

Three different IVM media were used to determine the effect on porcine oocyte maturation rates. With those media being NCSU 37, TCM 199 and follicular fluid supplemented with follicle stimulating hormone (FSH) and luteinizing hormone (LH). The use of porcine follicular fluid was selected with the addition of FSH and LH to try mimic in vivo conditions. Porcine follicular fluid inclusion in IVM media has become more popular through the past years (Yoshida et al., 1993; Kikuchi and Kawai, 2000). This was then used to determine how much of an effect natural hormones have on the maturation of oocytes when compared to chemical based media. Gil et al. (2010) found that the most common media used for porcine IVM was NCSU 37, NCSU 23 and TCM 199; while Pyoos et al. (2018) showed that NCSU 37 performed better than NCSU 23 when used in an IVM system. The TCM 199 was selected as it was observed as being used in many previous studies. The NCSU media was included in the study but NCSU 23 was omitted in favour of NCSU 37 due to the results shown by Pyoos et al. (2018). The NSCU media contain either taurine, hypotaurine or sorbitol for use in IVM and IVC (Petters and Wells, 1993; Kikuchi and Kawai, 2000).

Maturation of the oocyte was determined by two visual traits seen under the microscope. The first being the expansion of the cumulus oocyte complex (COC) which can be classified into full expansion, partial expansion or partly naked (Alvarez et al., 2009). The oocytes that were fully expanded were selected for IVF and ES. The second indicator of maturation used in this study was the presence of a polar body extrusion. The polar body extrusion from an oocyte indicates maturation of the cell following the completion of meiosis I (Pyoos et al., 2018). The oocytes were completely denuded and observed under a microscope for the presence of a polar body extrusion (Fig. 2) (Alvarez et al., 2009).

This study found that there were no significant differences among the three treatments selected for IVM (Table 2). The percentage of polar body extrusion for NCSU 37 was $25.3 \%$ of oocytes and was numerically lower when compared to TCM 199 and mpFF. TCM 199 and mpFF had a polar body extrusion of 84.2 and $73.8 \%$ of oocytes observed, respectively.

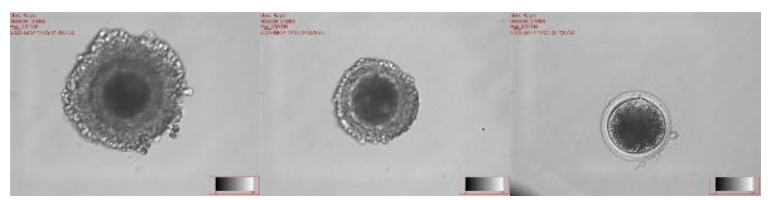

Fig. 1: Oocytes of grades A, B, and C from left to right (20x)

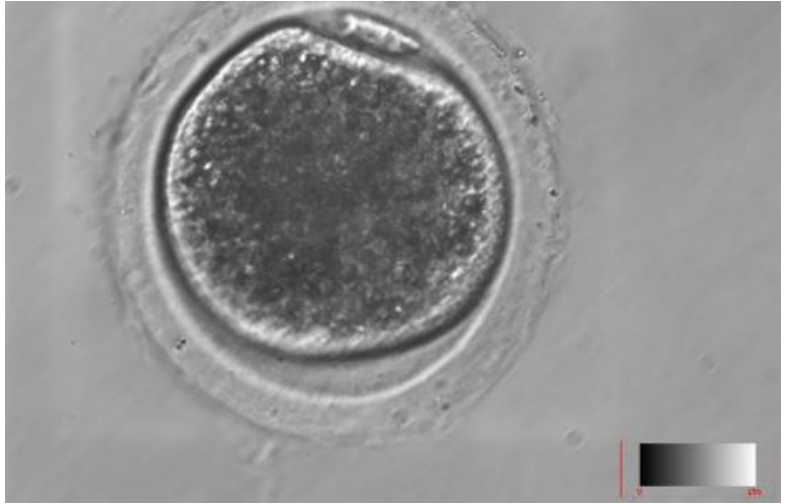

Fig. 2: An oocyte with a polar body (40x)

This is in contrast to the findings of Pyoos et al. (2018) who found that NCSU 37 had significantly higher rates (81.9 to $85.9 \%$ ), of oocytes with polar body formation, when compared to the alternative media used in their study. It can be made comparable that the NCSU 37 media used by Pyoos et al. (2018) was supplemented with gonadotropins while the other media that performed lesser, approximately $72 \%$, was supplemented with FSH and LH. Similarly, FSH and LH may have had an increased effect on cumulus cell expansion when paired with follicular fluid in this study.

Nevertheless, the potential of IVM media has increased since the early 2000s and this has allowed researchers to collect immature oocytes to place them in the specialized media. This improvement in IVM has allowed for the immature oocytes to have a 20 to $30 \%$ chance of progressing to the blastocyst stage (Gil et al., 2010; Appeltant et al., 2016). Therefore, the selection of IVM media will have a domino effect on the ability to progress to the blastocyst stage and thereafter, live births.

It has also been shown that the maturation of oocytes from prepubertal gilts has a lower rate of blastocyst formation when placed in follicular fluid obtained from the same ovaries or other prepubescent gilts (Pawlak et al., 2018). The follicular fluid acquired throughout the study was from different ovaries received on different days, this is due to the low yield of follicular fluid from a singular ovary. This could lead to a variation between the batches of media and discrepancies in the results found (Gadea et al., 2020).

The comparison of ES on oocytes was carried out to be compared to the effect of frozen-thawed semen on fertilization rates following IVF. Polyspermy has always been a major issue for porcine in vitro production (Gil et al., 2010; Pyoos et al., 2018; De Macedo et al., 2019). This was thought to be due to an issue during the maturation phase of in vitro production (IVP) that affects the cortical granule distribution of oocytes (Cran \& Cheng, 1986; Nagai, 1994). The rate of polyspermic penetration has been shown to be over $40 \%$ in the current porcine IVF systems (Romar et al., 2019; 
Gadea et al., 2020). However, in vivo incidences of polyspermy has been shown to exist when there is an increase in sperm numbers through artificial insemination (Hunter, 1973; Nagai, 1994).

Physiologically the normal development of an embryo occurs following fertilization. This comprises of meiotic resumption, cortical granule exocytosis, second polar body extrusion, pronuclear formation and the progression of the cell (Clift and Schuh, 2013; De Macedo et al., 2019). The process of ES on matured oocytes mimics this physiological progression without the need of sperm.

Following IVF and IVC the zygotes were checked for cleavage, which indicated success, as well as single cells and lysed cells. Single cell zygotes indicated that no growth was observed; this could be due to failure of activation, either through fertilization or ES, or could be due to issues with either of the gametes that prevented further development. Lysed cells were clear indicators of failure due to the death of the cells. Cell death could be caused by similar issues that inhibit growth, but it can only be speculated upon.

This study showed significant differences on cleavage rate of zygotes following fertilization with frozen-thawed sperm and ES. It was found that the cleavage rate of zygotes fertilized with frozen-thawed sperm was $48.1 \%$ (Table 3), while the ES method showed to have a cleavage rate of $56.8 \%$. One of the issues could be that the sperm may be of lesser quality and may not have the ability to successfully fertilize the oocyte. The results found by Lekola (2015) showed a $23 \%$ cleavage rate to the $2-3$ cell stage when using frozen-thawed sperm. Further, it has been shown recently that fertilization with frozen-thawed sperm can have an $80 \%$ farrowing rate in vivo (Didion et al., 2013; Estrada et al., 2014; Gadea et al., 2020).

The aforementioned issues of sperm quality may be summarized by sperm numbers, morphology and motility. Using the $\mathrm{SCA}^{\circledR}$ system, the sperm used in this study had a total motility of $49.45 \%$, with a rapid progression of $20.33 \%$. This shows that the motility of sperm used in this study is close to favourable when compared to results of 6090\% found (Quintero-Moreno et al., 2004). Another issue with fertilization with sperm is polyspermy, this is a wellknown issue within porcine reproductive technologies (Agung et al., 2013; Romar et al., 2016). Although, polyspermic zygotes may advance to the blastocyst stage at the same rate as monospermic zygotes and so are difficult to identify (Han et al., 1999a-b; Gil et al., 2010). Zygotes can be checked for two polar bodies presence $12 \mathrm{~h}$ post fertilization which is indicative of monospermic fertilization (Appeltant et al., 2016). It can also be made known that the proportion of successful monospermic zygotes would be $45 \%$ or less (Romar et al., 2016; Gadea et al., 2020). These findings deduced that the results received for embryo cleavage for the fertilization method may contain numbers of polyspermic embryos, but it would be difficult to differentiate between them and healthy embryos. It can then be suggested that further studies using IVF and ES comparatively are needed to understand more about the issues of polyspermy in the porcine reproductive technology industry.

Two in vitro culture media (cNCSU 37 and $\mathrm{cpFF}$ ) were selected to evaluate the effect on embryo cleavage rates. The $\mathrm{cpFF}$ was used to determine how much an effect a fluid present in early stages in vivo would have on late stage embryo growth. In this situation, the chemically specialized medium would contain the necessary constituents for IVC when compared to a natural medium, such as $\mathrm{pFF}$ which would not be present for in vivo embryo growth.

In this study, significant differences were found between cleavage rate of porcine embryos with the use of the IVC media, cNCSU 37 and cpFF. When using cNCSU 37 for IVC, the cleavage rate was $66.6 \%$ (Table 3). In contrast, the results showed that the cleavage rate for embryos when using $\mathrm{cpFF}$ was $45.7 \%$. The IVC of porcine oocytes is usually difficult as the rate of blastocyst formation remains at $30-40 \%$ (Gil et al., 2017; Cambra et al., 2020).

It was noted that the majority of embryo cleavage that did occur was to the two-cell stage (Fig. 3), with few reaching the three cell stage and several lysed cells being present. The majority of the replicates where $\mathrm{cpFF}$ was used for IVC resulted in a dark appearance which is indicative of cell death. Therefore, it follows that the presence of porcine follicular fluid, even with modifications, had a negative effect on embryo growth if there is continuous exposure. Although, it was found by Duarte et al. (2020) that the ability to reach metaphase II following fertilization was increased with the combination of NCSU 37 with pFF (Yoshioka et al., 2008).

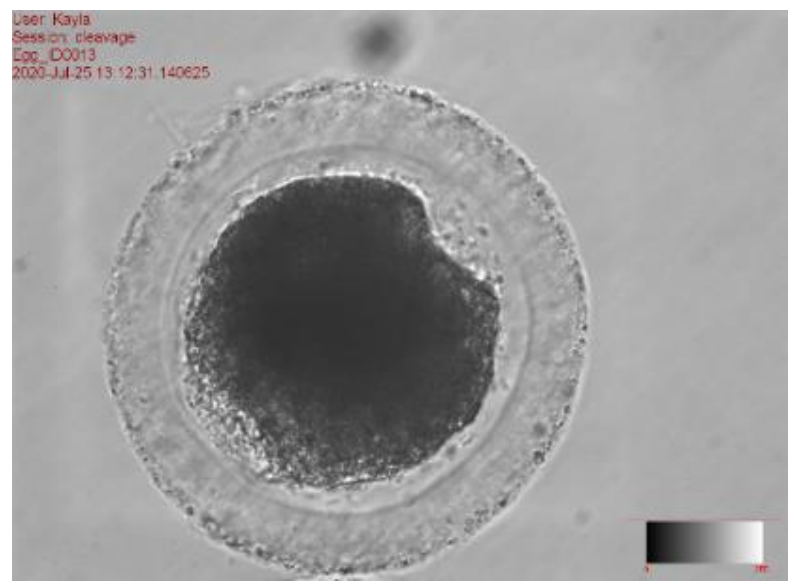

Fig. 3: An embryo advanced to the 2 cell stage (40x) 
Table 1: The means and standard error/deviations of the comparison of oocyte removal techniques Oocyte classification (grade)

\begin{tabular}{llllll} 
Method & Number of ovaries & A & B & C & Total \\
\hline Aspiration & 20 & $19.6 \pm 6.4^{\mathrm{b}}$ & $78.8 \pm 22.6^{\mathrm{b}}$ & $95.4 \pm 41.9^{\mathrm{b}}$ & $193.8 \pm 53.9^{\mathrm{b}}$ \\
Slicing & 20 & $45.6 \pm 15^{\mathrm{a}}$ & $241.2 \pm 102.5^{\mathrm{a}}$ & $201.8 \pm 86.7^{\mathrm{a}}$ & $488.6 \pm 159.2^{\mathrm{a}}$ \\
\hline
\end{tabular}

${ }^{\mathrm{ab}}$ Means with different superscript letters in the same column differed $(\mathrm{P} \leq 0.05)$

Table 2: The means and standard error/deviations of the comparison of maturation mediums on oocytes polar body extrusion

\begin{tabular}{llll}
\hline Media & Number of oocytes & Oocytes observed & Polar body status \\
\hline NCSU 37 & 159 & $26.5 \pm 18.2$ & $6.7 \pm 9.7$ \\
TCM 199 & 159 & $26.5 \pm 18.2$ & $22.3 \pm 29.03$ \\
mpFF & 158 & $26.3 \pm 18.3$ & $19.4 \pm 19.8$
\end{tabular}

Means do not differ in the same column $(\mathrm{P}>0.05)$

NCSU- North Carolina State University

TCM- Tissue Culture Medium

mpFF- Porcine follicular fluid modified for in vitro maturation

Table 3: The means and standard error/deviations of the comparison of electrical stimulation on oocytes and frozen-thawed semen on fertilization rates following IVF and the comparison of cell cleavage rates following IVC in two different culture mediums

\begin{tabular}{llllllll}
\hline Method & No. oocytes (IVF) & IVC medium & No. oocytes (IVC) & Lys & 1 cell & $2-4$ cell & Total cleaved \\
\hline ES & 234 & cNCSU37 & 120 & $19.3 \pm 15.3^{\mathrm{c}}$ & $38.9 \pm 25.1$ & $41.8 \pm 19.7^{\mathrm{ab}}$ & $80.7 \pm 15.3^{\mathrm{a}}$ \\
& & cpFF & 106 & $47.6 \pm 37.9^{\mathrm{ab}}$ & $27.1 \pm 21.7$ & $25.4 \pm 24.3^{\mathrm{bc}}$ & $52.4 \pm 37.8^{\mathrm{bc}}$ \\
FT & \multirow{2}{*}{243} & cNCSU37 & 112 & $26.2 \pm 21.9^{\mathrm{bc}}$ & $27.3 \pm 12.4$ & $46.5 \pm 18.2^{\mathrm{a}}$ & $73.8 \pm 21.9^{\mathrm{ab}}$ \\
& & cpFF & 103 & $56.9 \pm 38.9^{\mathrm{a}}$ & $31.2 \pm 29.6$ & $11.8 \pm 11.9^{\mathrm{c}}$ & $43.1 \pm 38.9^{\mathrm{c}}$ \\
\hline
\end{tabular}

abc Means with different superscript letters in the same column differed $(\mathrm{P} \leq 0.05)$

ES- Electrical stimulation

FT- Frozen-thawed

IVF- In vitro fertilization

IVC- In vitro culture

\section{Conclusion}

It was concluded that the slicing method was significantly better than the aspiration method. The slicing method procured both the highest quantity of oocytes as well as the highest quality oocytes. There were no significant differences found among the three maturation media (NCSU 37, TCM 199 and mpFF) on oocytes maturation rate in vitro. The ES method had a higher rate of zygote cleavage than IVF. The cpFF medium had lower rates of cleavage when compared to cNCSU 37.

\section{Acknowledgment}

Thanks are extended to the Germplasm Conservation and Reproductive Biotechnologies, ARC-AP for the use of facilities. The Tiger Brands abattoir for the supply of ovaries used throughout this study.

\section{Funding Information}

Acknowledgements for financial assistance are extended to the Agricultural Research Council (ARC) and Department of Agriculture Land Reform and Rural Development (DALRRD).

\section{Authors Contributions}

Kayla Honneysett, Masindi Mphaphathi, Edward Webb and Ayanada Maqhashu: Were involved with the design of the study, data collection, data analysis and writing of the manuscript. All authors read and approved the manuscript.

\section{Ethics}

Ethical clearance was obtained from Agricultural Research Council- Animal Production Campus (ARC$\mathrm{AP})$ for use in the Germplasm, Conservation, Reproduction and Biotechnologies (GCRB) laboratories, APAEC [2019/24]. Ethical clearance was also obtained from the University of Pretoria for laboratory work at the ARC-AP, NAS215/2020.

\section{References}

Agung, B., Otoi, T., Fuchimoto, D. I., Senbon, S., Onishi, A., \& Nagai, T. (2013). In vitro fertilization and development of porcine oocytes matured in follicular fluid. Journal of Reproduction and Development, 59(2), 103-106.

doi.org/10.1262/jrd.2011-050 
Alvarez, G. M., Dalvit, G. C., Achi, M. V., Miguez, M. S., \& Cetica, P. D. (2009). Immature oocyte quality and maturational competence of porcine cumulus-oocyte complexes subpopulations. Biocell, 33(3), 167.

Appeltant, R., Somfai, T., Kikuchi, K., Maes, D., \& Van Soom, A. (2016). Influence of co-culture with denuded oocytes during in vitro maturation on fertilization and developmental competence of cumulus-enclosed porcine oocytes in a defined system. Animal Science Journal, 87(4), 503-510. doi.org/10.1111/asj.12459

Armstrong, D. T., Holm, P., Irvine, B., Petersen, B. A., Stubbings, R. B., McLean, D., \& Seamark, R. F. (1992). Pregnancies and live birth from in vitro fertilization of calf oocytes collected by laparoscopic follicular aspiration. Theriogenology, 38(4), 667-678. doi.org/10.1016/0093-691X(92)90029-Q

Armstrong, D. T., Irvine, B. J., Earl, C. R., McLean, D., \& Seamark, R. F. (1994). Gonadotropin stimulation regimens for follicular aspiration and in vitro embryo production from calf oocytes. Theriogenology, 42(7), 1227-1236. doi.org/10.1016/0093-691X(94)90871-0

Baldassarre, H., Furnus, C. C., De Matos, D. G., \& Pessi, H. (1996). In vitro production of sheep embryos using laparoscopic folliculocentesis: alternative gonadotrophin treatments for stimulation of oocyte donors. Theriogenology, 45(3), 707-717. doi.org/10.1016/0093-691X(95)00417-7

Cambra, J. M., Martinez, C. A., Maside, C., RodriguezMartinez, H., Martinez, E. A., Gil, M. A., \& Cuello, C. (2020). The cytokine platelet factor 4 successfully replaces bovine serum albumin for the in vitro culture of porcine embryos. Theriogenology, 148, 201-207. doi.org/10.1016/j.theriogenology.2019.11.009

Clift, D., \& Schuh, M. (2013). Restarting life: fertilization and the transition from meiosis to mitosis. Nature reviews Molecular cell biology, 14(9), 549-562. https://www.nature.com/articles/nrm3643

Cran, D. G., \& Cheng, W. T. K. (1986). The cortical reaction in pig oocytes during in vivo and in vitro fertilization. Gamete Research, 13(3), 241-251. doi.org/10.1002/mrd.1120130307

Davids, M. P., Jooste, A., \& Meyer, F. H. (2014). Evaluating the South African pork value chain. Retrieved on, 6.

de Macedo, M. P., Glanzner, W. G., Rissi, V. B., Gutierrez, K., Currin, L., Baldassarre, H., \& Bordignon, V. (2019). A fast and reliable protocol for activation of porcine oocytes. Theriogenology, 123, 22-29.

doi.org/10.1016/j.theriogenology.2018.09.021
Didion, B. A., Braun, G. D., \& Duggan, M. V. (2013). Field fertility of frozen boar semen: A retrospective report comprising over 2600 AI services spanning a four year period. Animal reproduction science, 137(3-4), 189-196. doi.org/10.1016/j.anireprosci.2013.01.001

Duarte, D., Álvarez Gallardo, H., Pérez Reynozo, S., \& Torre Sánchez, J. F. D. L. (2020). In vitro production of porcine embryos with use of chemically semidefined culture media system. Revista mexicana de ciencias pecuarias, 11(1), 102-115. doi.org/10.22319/rmcp.v11i1.4757

Estrada, E., Rodríguez-Gil, J. E., Rocha, L. G., Balasch, S., Bonet, S., \& Yeste, M. (2014). Supplementing cryopreservation media with reduced glutathione increases fertility and prolificacy of sows inseminated with frozen-thawed boar semen. Andrology, 2(1), 88-99. doi.org/10.1111/j.20472927.2013.00144.x

Funahashi, H., Cantley, T.C. \& Day, B.N. (1997). Preincubation of cumulus-oocyte complexes before exposure to gonadotropins improves the developmental competence of porcine embryos matured and fertilized in vitro. Theriogenology 47(679-686). https://doi.org/https://doi.org/10.1016/S0093691X(97)00026-5

Gadea, J., Coy, P., Matás, C., Romar, R., \& Cánovas, S. (2020). Reproductive technologies in swine. In Reproductive Technologies in Animals (pp. 67-79). Academic Press. doi.org/10.1016/B978-0-12817107-3.00005-9

Gil, M. A., Cuello, C., Parrilla, I., Vazquez, J. M., Roca, J., \& Martinez, E. A. (2010). Advances in swine in vitro embryo production technologies. Reproduction in domestic animals, 45, 40-48. doi.org/10.1111/j.1439-0531.2010.01623.x

Gil, M. A., Martinez, C. A., Nohalez, A., Parrilla, I., Roca, J., Wu, J., \& Martinez, E. A. (2017). Developmental competence of porcine genome-edited zygotes. Molecular reproduction and development, 84(9), 814-821. doi.org/10.1002/mrd.22829

Hamano, S., \& Kuwayama, M. (1993). In vitro fertilization and development of bovine oocytes recovered from the ovaries of individual donors: A comparison between the cutting and aspiration method. Theriogenology, 39(3), 703-712. doi.org/10.1016/0093-691X(93)90255-4

Han, Y. M., Abeydeera, L. R., Kim, J. H., Moon, H. B., Cabot, R. A., Day, B. N., \& Prather, R. S. (1999). Growth retardation of inner cell mass cells in polyspermic porcine embryos produced in vitro. Biology of Reproduction, 60(5), 1110-1113. doi.org/10.1095/biolreprod60.5.1110 
Han, Y. M., Wang, W. H., Abeydeera, L. R., Petersen, A. L., Kim, J. H., Murphy, C., ... \& Prather, R. S. (1999). Pronuclear location before the first cell division determines ploidy of polyspermic pig embryos. Biology of reproduction, 61(5), 1340-1346. doi.org/10.1095/biolreprod61.5.1340

Hasler, J. F. (1994). Commercial applications of in vitro fertilization in cattle. The Compendium on continuing education for the practicing veterinarian (USA). https://agris.fao.org/agrissearch/search.do?recordID=US9634153

Hunter, R. H. F. (1973). Polyspermic fertilization in pigs after tubal deposition of excessive numbers of spermatozoa. Journal of Experimental Zoology, 183(1), 57-62. doi.org/10.1002/jez.1401830107

Khandoker, M. A. M., Imai, K., Takahashi, T., \& Hashizume, K. (2001). Role of gelatinase on follicular atresia in the bovine ovary. Biology of reproduction, 65(3), 726-732. doi.org/10.1095/biolreprod65.3.726

Kikuchi, K., Kashiwazaki, N., Noguchi, J., Shimada, A., Takahashi, R., Hirabayashi, M., \& Kaneko, H. (1999). Developmental competence, after transfer to recipients, of porcine oocytes matured, fertilized and cultured in vitro. Biology of reproduction, 60(2), 336-340. doi.org/10.1095/biolreprod60.2.336

Kikuchi, K. \& Kawai, Y. (2000). Medium preparation and general protocols for in vitro production of porcine embryos.

Kikuchi, K., Onishi, A., Kashiwazaki, N., Iwamoto, M., Noguchi, J., Kaneko, H., \& Nagai, T. (2002). Successful piglet production after transfer of blastocysts produced by a modified in vitro system. Biology of Reproduction, 66(4), 1033-1041. doi.org/10.1095/biolreprod66.4.1033

Kumar, S., Devi, B., Purkayastha, A., Bharti, P. K., Doley, S., \& Kadirvel, G. (2016). Porcine ovarian biometry, oocyte retrieval and quality of oocytes under different seasons in north east hill region. Indian J. Anim. Sci, 86, 300-303.

Lekola, K. P. M. (2015). Improvement of cattle oocyte retrieval techniques and hormonal influence on in vitro embryonic development (Doctoral dissertation, University of Limpopo). http://ulspace.ul.ac.za/handle/10386/1580

Long, C. R., Dobrinsky, J. R., \& Johnson, L. A. (1999). In vitro production of pig embryos: comparisons of culture media and boars. Theriogenology, 51(7), 1375-1390. doi.org/10.1016/S0093-691X(99)00081-3

Marques, M. G., de Barros, F. R. O., Goissis, M. D., Giassetti, M. I., Assumpção, M. E. O. D. A., \& Visintin, J. A. (2015). Effect of oocyte recovery techniques on in vitro production of swine embryos. Open Journal of Animal Sciences, 5(04), 467. https://www.scirp.org/html/10-1400372_60314.htm

Nagai, T. (1994). Current status and perspectives in IVMIVF of porcine oocytes. Theriogenology, 41(1), 73-78. doi.org/10.1016/S0093-691X(05)80051-2
Nagai, T., Funahashi, H., Yoshioka, K. \& Kikuchi, K. (2006). Update of in vitro production of porcine embryos. Front. Biosci. 11(2565-2573).

Nedambale, T. L., Dinnyes, A., Groen, W., Dobrinsky, J. R., Tian, X. C., \& Yang, X. (2004). Comparison on in vitro fertilized bovine embryos cultured in KSOM or SOF and cryopreserved by slow freezing or vitrification. Theriogenology, 62(3-4), 437-449. doi.org/10.1016/j.theriogenology.2003.10.020

Pawlak, P., Warzych, E., Cieslak, A., Malyszka, N., Maciejewska, E., Madeja, Z. E., \& Lechniak, D. (2018). The consequences of porcine IVM medium supplementation with follicular fluid become reflected in embryo quality, yield and gene expression patterns. Scientific reports, 8(1), 1-12. https://www.nature.com/articles/s41598-01833550-4

Petters, R.M., \& Wells, K.D. (1993). Culture of pig embryos. J. Reprod. Fertil. Suppl. 48, 61-73.

Pyoos, G.M., Maqhashu, A.M., Scholtz, M.M. \& Nedambale, T.L. (2018). The comparison of three media on the in vitro maturation rate of pig oocytes. South African J. Anim. Sci. 48(1026-1031). https://doi.org/10.4314/sajas.v48i6.4.

Quintero-Moreno, A., Rigau, T., \& Rodriguez-Gil, J. E. (2004). Regression analyses and motile sperm subpopulation structure study as improving tools in boar semen quality analysis. Theriogenology, 61(4), 673-690. doi.org/10.1016/S0093-691X(03)00248-6 doi.org/10.1016/0093-691X(92)90249-Q

Robinson, J. (2018). The pig industry in South Africa. http://southafrica.co.za/pig-industry-south-africa.html

Romar, R., Cánovas, S., Matás, C., Gadea, J., \& Coy, P. (2019). Pig in vitro fertilization: Where are we and where do we go?. Theriogenology, 137, 113-121. doi.org/10.1016/j.theriogenology.2019.05.045

Romar, R., Funahashi, H., \& Coy, P. (2016). In vitro fertilization in pigs: New molecules and protocols to consider in the forthcoming years. Theriogenology, 85(1), 125-134.

doi.org/10.1016/j.theriogenology.2015.07.017

SAS. (1999). SAS/STAT User's Guide.

Schoevers, E. J., A., Kidson, J. H. M., Verheijden, \& M. M. Bevers. (2003). Effect of follicle-stimulating hormone on nuclear and cytoplasmic maturation of sow oocytes in vitro. Theriogenology. 59(9), 2017 2028. https://doi.org/https://doi.org/10.1016/S0093691X(02)01288-8

Shapiro, S. S., \& Wilk, M. B. (1965). An analysis of variance test for normality (complete samples). Biometrika, 52(3/4), 591-611. doi.org/10.2307/2333709 
Shirasawa, H., Kumagai, J., Sato, W., Kumazawa, Y., Sato, N., \& Terada, Y. (2013). Retrieval and in vitro maturation of human oocytes from ovaries removed during surgery for endometrial carcinoma: a novel strategy for human oocyte research. Journal of assisted reproduction and genetics, 30(9), 1227-1230. https://link.springer.com/article/10.1007/s10815-0130040-z

doi.org/10.1095/biolreprod.105.048553

Tait-Burkard, C., Doeschl-Wilson, A., McGrew, M. J., Archibald, A. L., Sang, H. M., Houston, R. D., \& Watson, M. (2018). Livestock 2.0-genome editing for fitter, healthier and more productive farmed animals. Genome biology, 19(1), 1-11. https://genomebiology.biomedcentral.com/articles/1 0.1186/s13059-018-1583-1

Tatemoto, H., Muto, N., Sunagawa, I., Shinjo, A., \& Nakada, T. (2004). Protection of porcine oocytes against cell damage caused by oxidative stress during in vitro maturation: role of superoxide dismutase activity in porcine follicular fluid. Biology of reproduction, 71(4), 1150-1157. doi.org/10.1095/biolreprod.104.029264

Yamauchi, N., Sasada, H., Sugawara, S., \& Nagai, T. (1996). Effect of culture conditions on artificial activation of porcine oocytes matured in vitro. Reproduction, fertility and development, 8(8), 1153-1156. https://www.publish.csiro.au/rd/rd9961153
Yoon, K. W., Shin, T. Y., Park, J. I., Roh, S., Lim, J. M., Lee, B. C., \& Lee, E. S. (2000). Development of porcine oocytes from preovulatory follicles of different sizes after maturation in media supplemented with follicular fluids. Reproduction, Fertility and Development, 12(4), 133-139. https://www.publish.csiro.au/RD/RD00027

Yoshida, M., Mizoguchi, Y., Ishigaki, K., Kojima, T., \& Nagai, T. (1993). Birth of piglets derived from in vitro fertilization of pig oocytes matured in vitro. Theriogenology, 39(6), 1303-1311. doi.org/10.1016/0093-691X(93)90232-T

Yoshioka, K., Suzuki, C., \& Onishi, A. (2008). Defined system for in vitro production of porcine embryos using a single basic medium. Journal of Reproduction and Development, 54(3), 208-213. doi.org/10.1262/jrd.20001

Zeringue, H. C., Rutledge, J. J., \& Beebe, D. J. (2005). Early mammalian embryo development depends on cumulus removal technique. Lab on a Chip, 5(1), 86-90. doi.org/10.1039/B316494M 